\title{
SUB -THZ TRAVELING WAVE AMPLIFIERS BASED ON THE DOUBLE CORRUGATED WAVEGUIDE
}

\author{
Claudio Paoloni Mauro Mineo \\ Engineering Department \\ Lancaster University \\ Lancaster, UK
}

The importance of the sub-THz $(0.1-1 \mathrm{THz})$ portion of the spectrum is recognized fundamental for many applications. In particular, the region around $0.22 \mathrm{THz}$ is suitable for high data rate communications ${ }^{1}$ and imaging due the low atmospheric attenuation window. However, high power is needed in this frequency range to provide a reasonable length of the transmission path.

Vacuum electron devices represent so far the only viable solution for relatively output power at those frequencies. Wideband Traveling Wave Tube Amplifiers (TWTAs) operating in the $0.22 \mathrm{THz}$ range were demonstrated with relevant performance ${ }^{2}$.

The high cost of TWTAs still prevents their wide market diffusion. The double corrugated waveguide (DCW) is a slow wave structure of easy fabrication and assembly. A TWT based on the DCW is presented as possible affordable approach $^{3}$. A relative high output power $(3.7 \mathrm{~W})$ over a wide bandwidth $(20 \mathrm{GHz})$ centered at $0.23 \mathrm{THz}$ was demonstrated, with $13 \mathrm{kV}$ beam voltage and $30 \mathrm{~mA}$ beam current.

The wideband performance is related to the superposition of the beam line with the dispersion curve over a wide frequency region. The optimization of the DCW dimensions is then a crucial step to assure wideband amplification. A study on the definition of the widest synchronism region is proposed. The aim is to extend the region included between the lower and upper cutoff frequencies of the dispersion curve and to control the its slope, maintaining a low beam voltage and suitable values of interaction impedance and losses.

1. Koenig, S.; Antes, J.; Lopez-Diaz, D.; Schmogrow, R.; Zwick, T.; Koos, C.; Freude, W.; Leuthold, J.; Kallfass, I., "20 Gbit/s wireless bridge at $220 \mathrm{GHz}$ connecting two fiberoptic links," IEEE/OSA Journal of Optical Communications and Networking, vol.6, no.1, pp.54,61, Jan. 2014

2. Shin, Y.-M.; Baig, A.; Barnett, L.R.; Wen-Ching Tsai; Luhmann, N.C., "System Design Analysis of a $0.22-\mathrm{THz}$ Sheet-Beam Traveling-Wave Tube Amplifier," IEEE Trans. Electron Devices, pp.234,240, Jan. 2012

3. Paoloni, C.; Mineo, M., "Double Corrugated Waveguide for G-Band Traveling Wave Tubes," IEEE Trans. on Electron Devices, vol.61, no.12, pp. 4259-4263, Dec. 2014. 